\title{
Optimal Pricing Strategy of Electric Vehicle Charging Station for Promoting Green Behavior Based on Time and Space Dimensions
}

\author{
Xiaomin Xu $\mathbb{D}^{1,2}$ Dongxiao Niu, ${ }^{1,2}$ Yan Li, ${ }^{1,2}$ and Lijie Sun ${ }^{1,2}$ \\ ${ }^{1}$ School of Economics and Management, North China Electric Power University, Beijing 102206, China \\ ${ }^{2}$ Beijing Key Laboratory of New Energy and Low-Carbon Development (North China Electric Power University), \\ Beijing 102206, China \\ Correspondence should be addressed to Xiaomin Xu; xuxiaomin0701@126.com
}

Received 5 June 2020; Revised 3 July 2020; Accepted 16 July 2020; Published 11 August 2020

Academic Editor: Sang-Bing Tsai

Copyright ( $\odot 2020$ Xiaomin Xu et al. This is an open access article distributed under the Creative Commons Attribution License, which permits unrestricted use, distribution, and reproduction in any medium, provided the original work is properly cited.

\begin{abstract}
Considering that the charging behaviors of users of electric vehicles (EVs) (including charging time and charging location) are random and uncertain and that the disorderly charging of EVs brings new challenges to the power grid, this paper proposes an optimal electricity pricing strategy for EVs based on region division and time division. Firstly, by comparing the number of EVs and charging stations in different districts of a city, the demand ratio of charging stations per unit is calculated. Secondly, according to the demand price function and the principle of profit maximization, the charging price between different districts of a city is optimized to guide users to charge in districts with more abundant charging stations. Then, based on the results of the zonal pricing strategy, the time-of-use (TOU) pricing strategy in different districts is discussed. In the TOU pricing model, consumer satisfaction, the profit of power grid enterprises, and the load variance of the power grid are considered comprehensively. Taking the optimization of the comprehensive index as the objective function, the TOU pricing optimization model of EVs is constructed. Finally, the nondominated sorting genetic algorithm (NSGA-II) is introduced to solve the above optimization problems. The specific data of EVs in a municipality directly under the Central Government are taken as examples for this analysis. The empirical results demonstrate that the peak-to-valley ratio of a certain day in the city is reduced from $56.8 \%$ to $43 \%$ by using the optimal pricing strategy, which further smooth the load curve and alleviates the impact of load fluctuation. To a certain extent, the problem caused by the uneven distribution of electric vehicles and charging stations has been optimized. An orderly and reasonable electricity pricing strategy can guide users to adjust charging habits, to ensure grid security, and to ensure the economic benefits of all parties.
\end{abstract}

\section{Introduction}

Since the 1990s, environmental pollution and fossil-energy shortages have become increasingly serious [1]. Thus, energy-saving and environmentally friendly electric vehicles (EVs) have attracted worldwide attention [2]. The United States, Japan, and many countries in Europe have formulated relative policies to encourage the development of the EV industry [3]. Through a series of policy incentives, the Chinese government has also strongly supported the development of its domestic EV industry to promote the production and sales of EVs, as well as the construction of charging infrastructure [4]. According to statistics from the Ministry of Industry and Information Technology of China, the average fuel consumption of fuel passenger vehicles was $6.7 \mathrm{~L} / 100 \mathrm{~km}$ in 2017 . Calculated by kilometers traveled, the emission factor of greenhouse gases was $152 \mathrm{~g} / \mathrm{km}$. In comparison, the average fuel consumption of pure electric passenger vehicles was $16.2 \mathrm{kWh} / 100 \mathrm{~km}$, and the emission factor of greenhouse gases was $0 \mathrm{~g} / \mathrm{km}$ [5]. According to the data released by the Ministry of Ecology and Environment of China, the emission factor of air pollutants for pure electric passenger vehicles during operation phase is $0 \mathrm{~g} / \mathrm{km}$. Thus, EVs can reduce not only greenhouse gas emissions [6] but also the emissions of pollutants such as hydrocarbons [7]; both reductions are conducive to achieve green, low-carbon travel, to mitigate the global warming and climate change crisis, and to alleviate environmental pollution [8]. Further, 
EVs can help promote the consumption of renewable energy and reduce the dependence on fossil energy [9], thereby promoting the development of a low-carbon economy and the sustainable development of society. EVs are therefore an important means in solving energy, environmental, and transportation problems [10]. EVs encourage people to adopt green and low-carbon travel, and EVs have promising development prospects as well [11].

With continuous breakthroughs in key EV technologies and the increasing improvements in charging infrastructure [12], countries around the world have accelerated EV technological innovation and have actively participated in market competition [13, 14]. According to the "Global EV Outlook 2018" released by the International Energy Agency (IEA), the global electric vehicle market has grown to more than 3 million vehicles in 2017, with an increase of 54\% yearover-year. According to this estimation, global electric vehicle ownership will reach 13 million by 2030. By the end of June 2018, there were 19.9 million new energy vehicles in China, of which 1.62 million were pure EVs, leading world production. As the Chinese government attaches great importance to the development of the electric vehicle industry, a series of policies has been issued in macroplanning, industry management, financial subsidies, technological innovation, and infrastructure construction [15]. According to data released by the China Association of Automobile Manufacturers, production and sales of EVs have been steadily increasing from 2013 to 2018.

As seen in Figure 1, sales of pure EVs increased the most in 2014 and 2015, indicating that the industry development plan formulated by the government in the earlier period and the current subsidy policy have achieved remarkable results. In 2018, sales of pure EVs increased by more than $50 \%$, showing a strong momentum in the development of the electric vehicle market. With the rapid growth of electric vehicle ownership, China also has the fastest growth in charging infrastructure (according to the data released by China Electric Vehicle Charging Infrastructure Promotion Alliance, there were approximately 7154 new public charging stations installed every month in 2018, which is $18.2 \%$ higher than that in 2017). At present, China has become the country with the most charging stations in the world [16]. The distribution of charging stations in various provinces and cities in China (excluding Hong Kong, Macao, and Taiwan) at the end of 2018 is shown in Figure 2. It can be seen that most provinces in China are equipped with charging facilities. Among them, Beijing, Shanghai, Guangdong, and Jiangsu are the leaders with more than 30000 charging stations.

With the promulgation and implementation of a series of policies and incentives by the Chinese government, the use of EVs has been widely promoted [17]. As such, problems related to EV charging have gradually emerged, mainly in the following three aspects.

Firstly, large-scale, unguided, and spontaneous EV charging can affect the safe operation of the electric power grid, which is reflected in load balance, power quality, and power grid construction planning [18]. The rapid increase in the number of EVs and charging stations suggests that EVs are an important load on the power grid. When large numbers of EVs charge during peak hours, it further aggravates the peak-to-valley difference and increases the burden on the power grid. Even worse, when EVs charge in a disordered manner, it enlarges the difficulty of peak shaving, brings incremental cost of generator, increases pressure on electricity transmission and on distribution networks, and reduces the security and reliability of the power grid [19]. In addition, charging EVs will create negative effects on power quality and increase the harmonic content of the power grid. For power generation, the large-scale connection of EVs to the power grid places higher requirements on the capacity of the generator assembly [20]. For transmission and distribution networks, if there is large-scale EV charging at peak hours, the charging may lead to overload, making the construction planning of future power systems much more uncertain [21].

Secondly, unreasonable charging pricing mechanisms and methods have led to a failure of EVs being able to respond effectively to demand [22]. When large numbers of EVs charge in an orderly way, the peak-to-valley difference can be reduced, and the grid load characteristics can be improved. Moreover, as distributed energy storage facilities, EVs can adjust their real-time charging plans to meet the needs of the electric power system [23]. Price is an important means to guide EVs in playing their role in demand response. However, except in Beijing, the EV charging service as a market has not started up in other places. Electric vehicles have uniform prices set by the government, with the pricing mechanism having little effect on guidance and adjustment by EV users. Under this circumstance, it is difficult for EVs to play their role in peak shaving and valley filling [24] and in reducing the operating cost of the system [25].

Thirdly, there also exist some problems in charging stations, such as unbalanced utilization, high maintenance costs, and poor revenue in the charging business. Generally, the utilization rate of charging stations, such as stations for public transportation and logistics, which are constructed and operated according to the specific needs of their users, is relatively high [26]; thus, the result is congestion in the charging queue during peak hours. Meanwhile, other charging stations, especially those located in remote areas, experience low utilization rates. Even a part of the proportion of charging stations is $0 \%$. The utilization rate of charging stations in each area is extremely uneven, causing idleness and wasting of resources to certain extents (from the perspective of revenue, even the charging stations with high utilization rates have very poor economic benefits because of the large preinvestments, high operating costs, and single source of income [27]).

Using the above context, and fully considering the charging demand of users and the impact of safe operation of charging stations, this paper explores how to formulate a reasonable and orderly charging strategy and how to formulate an effective price response mechanism for electric vehicles. Through the reasonable and orderly guidance of user behavior, we can reduce not only the peak-valley difference in grid load but also the charging costs for users. To 


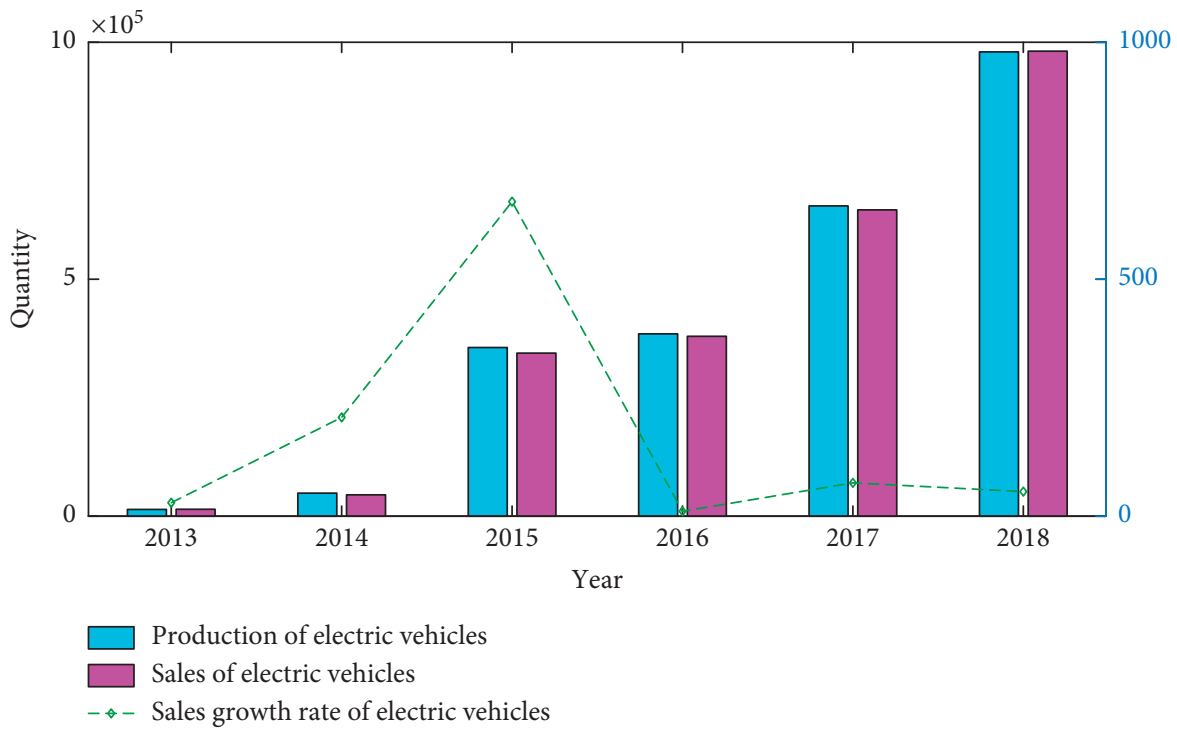

Figure 1: Production and sales of pure electric vehicles from 2013 to 2018.

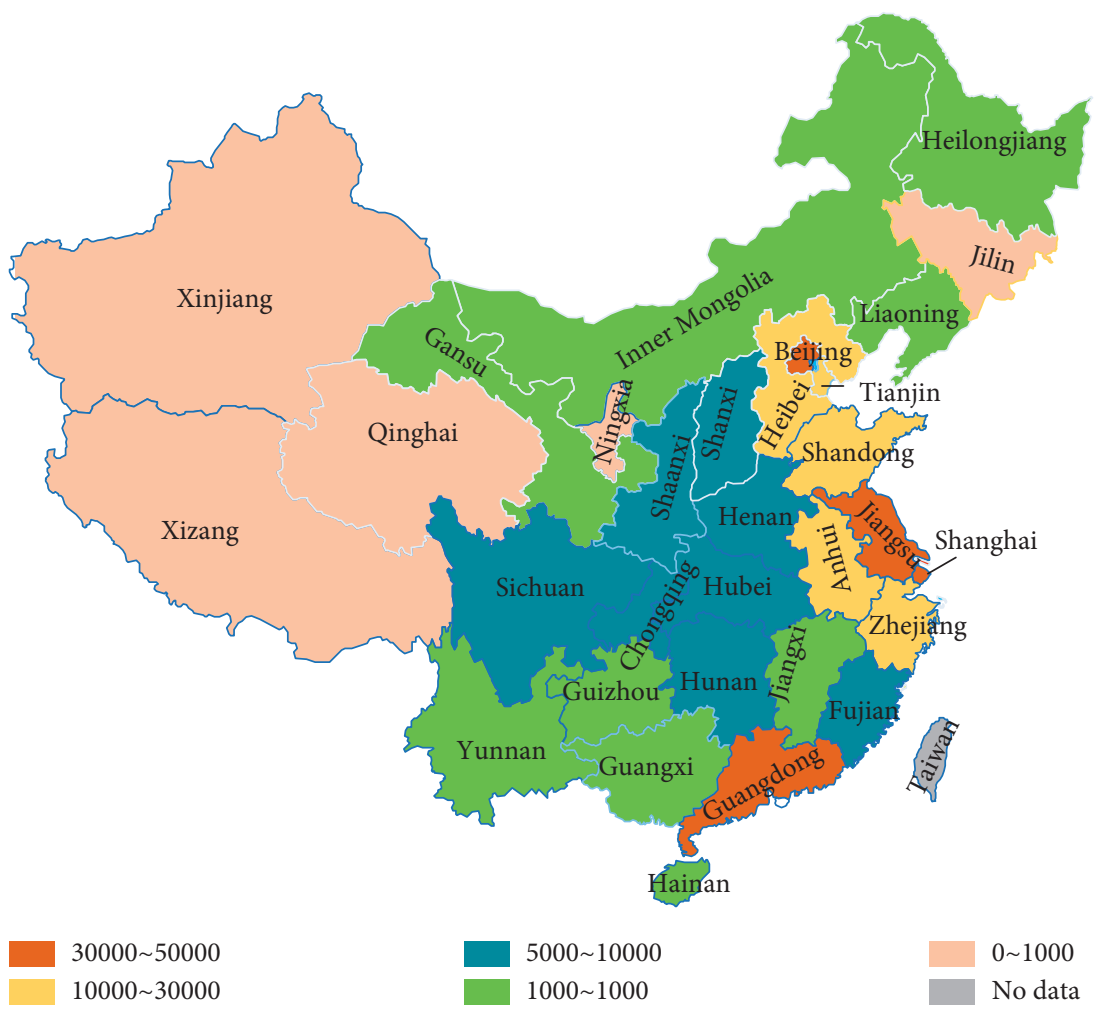

Figure 2: Distribution of electric vehicle charging stations in major provinces and cities in China (excluding Hong Kong, Macao, and Taiwan).

guide the orderly charging of electric vehicles, users can assist the grid frequency modulation to ensure the safe and stable operation of the power system. Therefore, it is of great significance to optimize the pricing strategy of electric vehicle charging stations. Thus, the organization of the rest of this paper is as follows. Section 2 summarizes the existing research literature. Section 3 introduces the model description and construction process. Section 4 describes the empirical analysis based on the modeling process and discusses the results. Section 5 summarizes the conclusions.

\section{Literature Review}

With the depletion of fossil fuels and the aggravation of environmental problems, electric vehicles, as new energy vehicles, have great potential in reducing environmental 
pollution and greenhouse gas emissions. However, with an increasing number of electric vehicles being connected to the grid for charging, the unreasonable charging plan of electric vehicles may have a great impact on the safe operation and economic benefits of the grid system. Therefore, a reasonable arrangement of the orderly charging of electric vehicles has become a major research trend. In view of the above problems, scholars in China and abroad have put forward many research methods for orderly charging. These methods can be summed up in two principle ways: one method is a direct load control method, and the other method is based on pricing strategy.

The direct load control method describes controlling the charging power of the charging station by the distribution network dispatching center or charging station and charging on the basis of meeting the system safety and vehicle charging requirements [28]. Qi et al. [29] proposed a charging control method combining online control and offline control, which can charge by controlling charging power. The current academic studies on EV charging stations mainly focus on a pricing mechanism. The research can be divided into the following categories. On the one hand, some studies mainly consider the technical factor of EV charging on the power grid to design the pricing mechanism. In other words, the cost of the charging technology is the most important factor. Salah and Flath [30] applied a deadline differentiated pricing scheme to incentivize flexible loads and claimed that varying PV capacity and the costs of conventional generation were the main factors. He et al. [31] formulated a multiclass combined distribution and assignment model, estimated electrical loads on the power distribution network, and optimized electricity prices at public charging stations and road tolls. Due to the high technical cost, this kind of pricing strategy often led to the charging price exceeding affordability for local residents, which is not conducive to the development of EVs.

On the other hand, some studies mainly consider the social and economic factors such as the developmental status of EVs, residents purchasing power, and the public attributes of electric products to the design the pricing mechanism. This kind of pricing strategy can be further divided into three categories: electricity consumption-based pricing, time-ofuse pricing, and zonal pricing. The electricity consumptionbased pricing strategy aims at reducing the electric load in peak hours and managing the charging behavior by EVs through controlling the amount of power supplied in corresponding time periods. The time-of-use pricing strategy is more mature [32]. The main idea is to encourage EV users to consume less electricity during the peak time period and more electricity during the valley time period, in order to guide the orderly charging of EVs. This method realizes the role of load adjustment for the power grid and reduces load fluctuation and the associated adverse effects when large numbers of EVs access the power grid. According to existing studies, peak-valley pricing $[2,33]$ and time-of-use pricing $[34,35]$ can mitigate the negative effects caused by the aggregate charging behavior of EVs to a certain extent and can play a better role in leveraging pricing. However, there exist corresponding deficiencies in flexibility and adaptability. Real-time pricing mechanisms [27, 36, 37] have been less studied due to related technological restrictions. The zonal pricing strategy mainly works by analyzing the utilization ratio of charging stations in different regions to guide users' charging behavior. Dong et al. [38] developed a double-layer optimization model to redistribute the charging load of EVs to optimize the charging pricing scheme and minimize the total voltage magnitude deviation of distribution networks [39]. Li et al. [4] took the users' charging time and space constraints into consideration to minimize the cost of each EV user. From the perspective of the participants, there are three research perspectives. The first is a pricing strategy that prioritizes the interests of the power grid and charging stations. For instance, Li et al. [40] put forward a charging pricing strategy that would improve the economic benefits of electric power enterprises. The second is a pricing strategy with priority given to EV users' interests, such as $\mathrm{Pu}$ et al. [41] who established a customer satisfaction model and proposed a coordinated pricing strategy for charging stations based on multiagents. The last pricing strategy considers multiple participants' interests, for example, the multiobjective charging optimization model based on time-of-use price with the security of power grid operation proposed by Cui et al. [42]. In this model, the individual needs of users and the interests of all parties are both addressed. Recent studies have changed from simply ensuring the maximization of one participant's interests to considering the common interests of multiple participants.

In summary, most of the current works only consider a single factor in the design of a pricing strategy. However, a single time-of-use (TOU) pricing strategy cannot solve the contradiction between charging congestion and charging station abandonment by EVs nor can a single zonal pricing strategy alleviate the impact of large-scale EV charging on the power grid during peak usage periods. Only by examining the two dimensions of zonal and TOU pricing simultaneously can we formulate effective strategies to solve the above problems. There are currently few studies focused on comprehensive analysis of multifactor pricing strategies, which is an area that requires further exploration and more detailed work. Accordingly, studies on multifactor, multidimension, and multiobjective pricing strategy are of great significance in motivating and guiding EV users to choose the appropriate time and location for charging. Moreover, it is conducive to improve the utilization efficiency of charging stations, alleviate the negative effects on the power grid, enhance the demand response ability, and improve the economic benefits of EV charging services.

In the previous research, the optimal pricing model and strategy of EV charging stations for the promotion of green and low-carbon behavior are proposed from two dimensions: space and time [43]. A multiobjective optimization model for centralized charging of EVs based on zonal and TOU pricing is put forward to formulate an optimal pricing strategy for EV charging. Firstly, through the demand of EVs for unit charging stations in different regions, the zonal pricing model is constructed based on the demand price function with the goal of maximizing profits. Through price differences, the model can guide users to transfer from 
regions where the charging stations are in short supply to regions where the charging stations are in oversupply. Secondly, taking the comprehensive consideration of user utility maximum, grid revenue maximization, and grid fluctuation minimum, this paper constructs a TOU pricing objective function and constraints. Thirdly, nondominated sorting genetic algorithm II (NSGA-II), which is a mature multiobjective optimization algorithm, is utilized to optimize the pricing strategy [44]. The empirical data from a municipality directly under the Central Government is used to verify the validity of this model. By exploring the pricing strategies for different periods in different regions and further refining the charging price classification of EVs, the utilization rate of charging stations in different regions can be improved, reducing the impact on the power grid, but it can also decrease users' charging costs and improve the revenue of charging stations through dynamic pricing strategies. Thus, a win-win situation can be achieved.

\section{Model Description and Construction}

3.1. Zonal Optimal Pricing Model. Based on the demand and price, the demand price function of electric vehicles is constructed, and then the profit function is established. Profit can be obtained from charging revenue and then subtracting costs, which include electricity costs, construction costs, operation and maintenance costs, and bank interest, to obtain the optimal pricing strategy of each region through calculation.

Establish the demand price function of electric vehicle charging in each region:

$$
Q_{d}^{i}=d\left(P_{i}\right)=b_{i}-a \bar{P}_{i} .
$$

Among them, $Q_{d}^{i}$ indicates the demand for electric vehicle charging in the area $i, b_{i}$ is a constant, which presents EV ownership of area $i, \bar{P}_{i}$ is the price for different regions, and $a$ is a coefficient. The formula reflects the relationship between the quantity of charging demand and the charging price. It is a monotonic decreasing function; that is, the demand decreases with the increase in charging price. We believe that for the regions with high demand for charging, we can set a higher charging price through the demand price function to increase the charging cost of electric vehicles to guide some electric vehicles to the neighboring regions that have lower demand for charging.

On this basis, the benefits of charging station operators cannot be ignored, we can establish a profit function:

$$
\begin{aligned}
L(\bar{P}) & =\sum_{i=1}^{n}\left[D_{i} \times\left(\bar{P}_{i}-p\right)(1+r)^{n}\right]-C, \\
D_{i} & =Q_{d}^{i} \times t,
\end{aligned}
$$

where $L(\bar{P})$ represents a profit function and $p$ expresses the electricity purchase price (units: yuan/kWh). $r$ represents the annual growth rate of electric vehicles. $t$ represents the charging capacity per car. $C$ represents the fixed cost of the charge station. Thus, the profit function is a quadratic function of price $P$ with respect to $L$, and the optimal solution of the function appears at the point where the first derivative is 0 ; namely,

$$
\operatorname{Max} L=\frac{d L}{d \bar{P}}=0 .
$$

Combining the ownership and demand of EVs in different regions, the optimal charging pricing of EVs in different regions can be obtained.

\subsection{Multiobjective Optimal Model for Time-of-Use Pricing (TOU Pricing)}

3.2.1. Objective Function. Taking the economic benefits of users and power grids, as well as the power quality, into account, this paper establishes a multiobjective pricing optimization model, which has the objective of maximizing the benefits for both users and the power grid and minimizing the fluctuation in the loads.

(1) Maximizing User Benefits. The purpose of setting a TOU price is to guide users to charge when the price of electricity is low to earn the price difference and reduce the peak-valley difference in grid load [45]. However, users are not willing to charge in all areas where price differences exist. Only when the differential value of electricity prices exceeds a certain range will users change their charging behavior and transfer the charging to a different region. In other words, we believe that there is a certain threshold for the transfer of electricity. Within the threshold range, users are willing to change their charging mode (transfer charging capacity). While beyond the threshold range, no matter how much the price changes, users are not willing to change their behavior. Figure 3 shows the relationship.

$x$ is the differential value of electricity price and $x_{1}$ represents the start threshold for users to change charging behavior. In the region which is less than $x_{1}$, the incentive effect of changing electricity price on users is ineffective. Similarly, electricity price spreads will not endlessly change users' charging behavior. $x_{2}$ represents the saturation threshold for users to change charging behavior. After this threshold, no matter how the price increases, the users' charging behavior will not change. $y$ represents the probability that the user will change his/her charging behavior or the probability of a power transfer.

This paper does not take the purchase cost of EVs into consideration, but only considers the user's satisfaction in both the electricity consumption mode and the cost expenditure after the implementation of the TOU price.

Through reading and summarizing the literature, the degree of satisfaction of electricity consumption mode can be calculated by the following formula [42]:

$$
\beta_{i}=1-\frac{\sum_{t=1}^{T}\left|\hat{g}_{i}^{t}-g_{e}\right| \times \Delta t}{\sum_{t=1}^{T} g_{i}^{t} \Delta t} .
$$

The satisfaction degree of the cost expenditure can be expressed as 


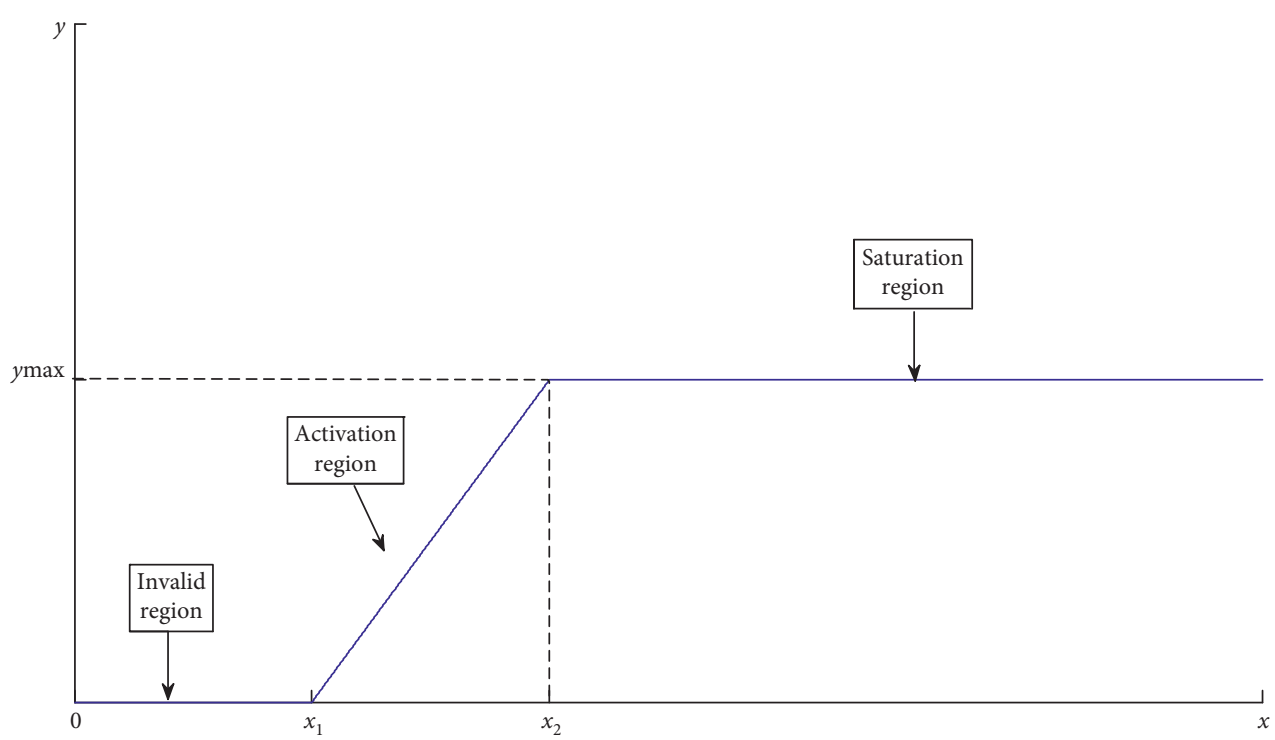

FIGURE 3: Charging behavior change (power transfer probability) diagram.

$$
\gamma_{i}=\frac{\sum_{t=t^{\prime}}^{t^{\prime}+m-1}\left(\widetilde{P_{i}^{t}}-\widetilde{P_{g}}\right) \times g_{i}^{t} \times \Delta t}{\sum_{t=t}^{t^{\prime}+m-1}\left(\widetilde{P_{f}}-\widetilde{P_{g}}\right) \times g_{i}^{t} \times \Delta t .}
$$

Among them, $\tilde{P}_{i}^{t}$ is the price for a period of time $i$; $P_{f}, P_{g}$ represent the peak hour price and trough price, respectively; $g_{i}$ is the charging power for $\mathrm{EV}$; $\widehat{g}_{i}^{t}$ is the charging power of the electric vehicle $i$ in the period $t$ when the single user has the greatest travel satisfaction; $\Delta t$ is the charging time; and $m$ is a time window for rolling optimization. The greater the difference between the optimized TOU price $\bar{P}_{i}$ and the original price is, the higher the satisfaction of users with charging charges is, and the greater the utility is.

To maximize user satisfaction, the objective function is set as follows:

$$
F_{1}=\max \sum_{i=1}^{N}\left(\alpha_{1} \beta_{i}+\alpha_{2} \gamma_{i}\right),
$$

where $\alpha_{1}, \alpha_{2}$ are the weight coefficient.

(2) Maximizing the Revenue of Power Grid. For power grid companies, dynamic electricity prices can make users of EVs choose a charging start time that is independent of their own needs for reducing charging costs. However, in the economic market, the goal of all industries is to maximize economic benefits. Power grid companies can also achieve this goal by setting a reasonable TOU price.

$$
\begin{aligned}
& F 2=\max \sum_{i=1}^{24} \sum_{j=1}^{T}\left[n \times \mu_{j} \times\left(\widetilde{P}_{i}-c\right) \times \Delta t\right], \\
& \mu_{j}=\frac{1}{N} \sum_{i=1}^{N} g_{i, j} .
\end{aligned}
$$

In this formula, $\mu_{j}$ represents the expected value of charging power for the time periods $j$ of an electric vehicle.
(3) Minimizing Load Fluctuation in Power Grid. A large number of decentralized and disorderly charging stations of EVs will create challenges for the safe and stable operation of the power system. As builders and operators of charging stations, power grid companies need to consider not only their own benefits, but also power quality and grid security as objectives. Through reasonable TOU pricing, users can be guided to charge at staggered peaks to suppress load fluctuations and facilitate the stable operation of the power grid.

The load fluctuation of the power system is incorporated into the objective function. The deviation between the total load and the average load level after considering the charging load of EVs is investigated. The objective functions are shown as follows:

$$
\begin{aligned}
F_{3} & =\min \left[\frac{1}{T} \sum_{t=1}^{T}\left(L_{t}+\sum_{i=1}^{n} g_{i}^{t}-\bar{g}\right)^{2}\right], \\
\bar{g} & =\frac{1}{T} \sum_{t=1}^{T}\left(L_{t}+\sum_{i=1}^{n} g_{i}^{t}\right) .
\end{aligned}
$$

Among them, $L_{t}$ is the basic load of the power grid at time $t$ and $\bar{g}$ represents the average load of the grid at time $t$.

\subsubsection{Constraint Conditions}

(1) Limit Constraints for TOU Price. The formulation of TOU prices should be within the price range that users can afford. To avoid excessive TOU pricing, it is necessary to restrict the fluctuation limits of TOU prices.

$$
\begin{gathered}
\widetilde{P}_{\min } \leq \widetilde{P}_{i} \leq \widetilde{P}_{\max }, \\
\widetilde{P}_{\mathrm{avr}}=\frac{1}{24} \sum_{i=1}^{24} \widetilde{P}_{i}, \\
\left|\widetilde{P}_{i}-\frac{\widetilde{P}_{f}+\widetilde{P}_{g}}{2}\right| \leq \varepsilon,
\end{gathered}
$$


where $\widetilde{P}_{\min }$ is the lower limit of the charging price for the $i$ th hour; $\widetilde{P}_{\max }$ is the upper limit of the charging price for the $i$ th hour; and $\widetilde{P}_{\text {avr }}$ is the floating benchmark value for the TOU price.

(2) Benefit Constraints of Power Grid. After implementing the TOU price, power grid companies should be guaranteed no reduction in revenue; that is,

$$
R_{1} \geq R_{0} \text {. }
$$

Specifically,

$$
\begin{aligned}
& \left(Q_{f}-\Delta Q_{\mathrm{fp}}-\Delta Q_{\mathrm{fg}}\right) \times \bar{P}_{f}+\left(Q_{p}-\Delta Q_{\mathrm{pg}}+\Delta Q_{\mathrm{fp}}\right) \times \bar{P}_{p} \\
& \quad+\left(Q_{g}+\Delta Q_{\mathrm{fg}}+\Delta Q_{\mathrm{pg}}\right) \times \bar{P}_{g} \geq\left(Q_{f}+Q_{p}+Q_{g}\right) \times P_{0} \\
& \Delta Q_{\mathrm{fp}}=\eta_{1} \Delta P_{\mathrm{fp}}, \\
& \Delta Q_{\mathrm{fg}}=\eta_{2} \Delta P_{\mathrm{fg}} \\
& \Delta Q_{\mathrm{pg}}=\eta_{3} \Delta P_{\mathrm{pg}} .
\end{aligned}
$$

According to the analysis of changes in users' charging behavior, it can be seen that the transfer of electricity is related to the price difference. In the formula, $Q_{f}, Q_{p}$, and $Q_{g}$ express the power demand in peak hours, flat hours, and valley hours, respectively; $\Delta Q_{\mathrm{fp}}$, $\Delta Q_{\mathrm{fg}}$, and $\Delta Q_{\mathrm{pg}}$ are peak-flat demand transfer, peak-valley demand transfer, and flat-valley demand transfer, respectively. $\bar{P}_{f}, \bar{P}_{p}$, and $\bar{P}_{g}$ are the prices at the peak, flat, and valley time periods, respectively; $P_{0}$ is the price before optimization; $\eta_{1}, \eta_{2}$, and $\eta_{3}$ are the demand transfer rates of the peak-to-flat, peak-to-valley, and flatto-valley periods, respectively.

(3) Probability Constraints of Charging Volume Transfer for Users. The power transfer probability of the TOF price is related to the price difference, and there remains a trigger threshold, which should meet the following constraints:

$$
c_{l} \leq \bar{P}_{f}-\bar{P}_{g} \text {. }
$$

(4) Voltage Offset Constraint. According to GB/T 12325-2008, the deviation limits of $20 \mathrm{kV}$ and the following three phases supply voltage are nominal voltage. Therefore, the normal range of node voltage $U_{i, j}$ is

$$
(1-7 \%) U_{N} \leq U_{i, j} \leq(1+7 \%) U_{N} \text {. }
$$

(5) Expectation Constraints of Voltage Qualification Rate. Voltage qualification rate (VQR) indicators $F_{\mathrm{VQR}}$ are the percentage of cumulative runtime $t_{\mathrm{VQR}}$ and the total runtime $T$ that the actual operating voltage deviation is within the limits.

$$
F_{\mathrm{VQR}}=\frac{t_{\mathrm{VQR}}}{T} \times 100 \% .
$$

The expected value $M_{\mathrm{VQR}, n}$ of voltage qualification rate of charging TOF price node $v$ can be expressed as

$$
M_{\mathrm{VQR}, n}=\frac{\sum_{j=1}^{96}\left(1-q_{n, j}\right)}{96} \times 100 \% .
$$

Among them, $q_{n, j}$ is the probability of voltage overrun of node $n$ in the time period $j$.

According to the regulation that the qualified rate of voltage in EN50160 is not less than 99\%, there are the following constraints:

$$
M_{\mathrm{VQR}, n} \geq 99 \% \text {. }
$$

3.3. Optimization Algorithm. In engineering practice, the mathematical model of many issues can be generalized as the multiobjective optimization problem, which is not similar to the single-objective optimization problem and its only one optimal solution. The solution is a set called the Pareto solution set. NSGA-II is robust and the noninferior solution has a uniform distribution in the target space and good convergence. With these characteristics, NSGA-II has become one of the popular multiobjective optimization algorithms and widely applied in engineering practice and various disciplines. The NSGA-II, an improved version of the NSGA, was proposed by Deb et al. [46]. The algorithm improved NSGA mainly by enhancing nondominated sorting efficiency, using crowding distance instead of sharing parameters, and introducing elitist-preserving approach, thus effectively overcoming the three major deficiencies of NSGA [47]. Meanwhile, by introducing a fast, nondominant sorting procedure, the computational complexity is greatly reduced, and the optimal preservation mechanism is provided. In this case, it can not only ensure the diversity of the population by using a parameterless niching operator [48] but also improve the ability of the optimization result to approach the Pareto optimal frontier [41]. NSGA-II mainly includes operators such as selection, crossover, and mutation. The selection mechanism is based on nondominated sorting and crowding distance. Simulated binary crossover (SBX) and polynomial mutation are utilized in NSGA-II, as stated by Murugan et al. [49].

The specific procedures of NSGA-II are described as follows and are shown in Figure 4.

Step 1. Set the algorithm parameters and the domain of values of each decision variable.

Step 2. Randomly generate the initial population $P_{0}$ in the domain of decision variables, that is, coding the feasible schemes and initializing a majority of pricing strategy schemes that satisfy the constraint conditions.

Step 3. Calculate the fitness value of each individual in the parent population $P_{0}$, which means calculating the values of multiple objective functions corresponding to each scheme according to the established multiobjective optimization mathematical model.

Step 4. Perform nondominated sorting on the current population according to their nondomination level based on the objective function values, enable individuals to enter their own front set, and calculate the crowding distance of individuals in each front separately. 


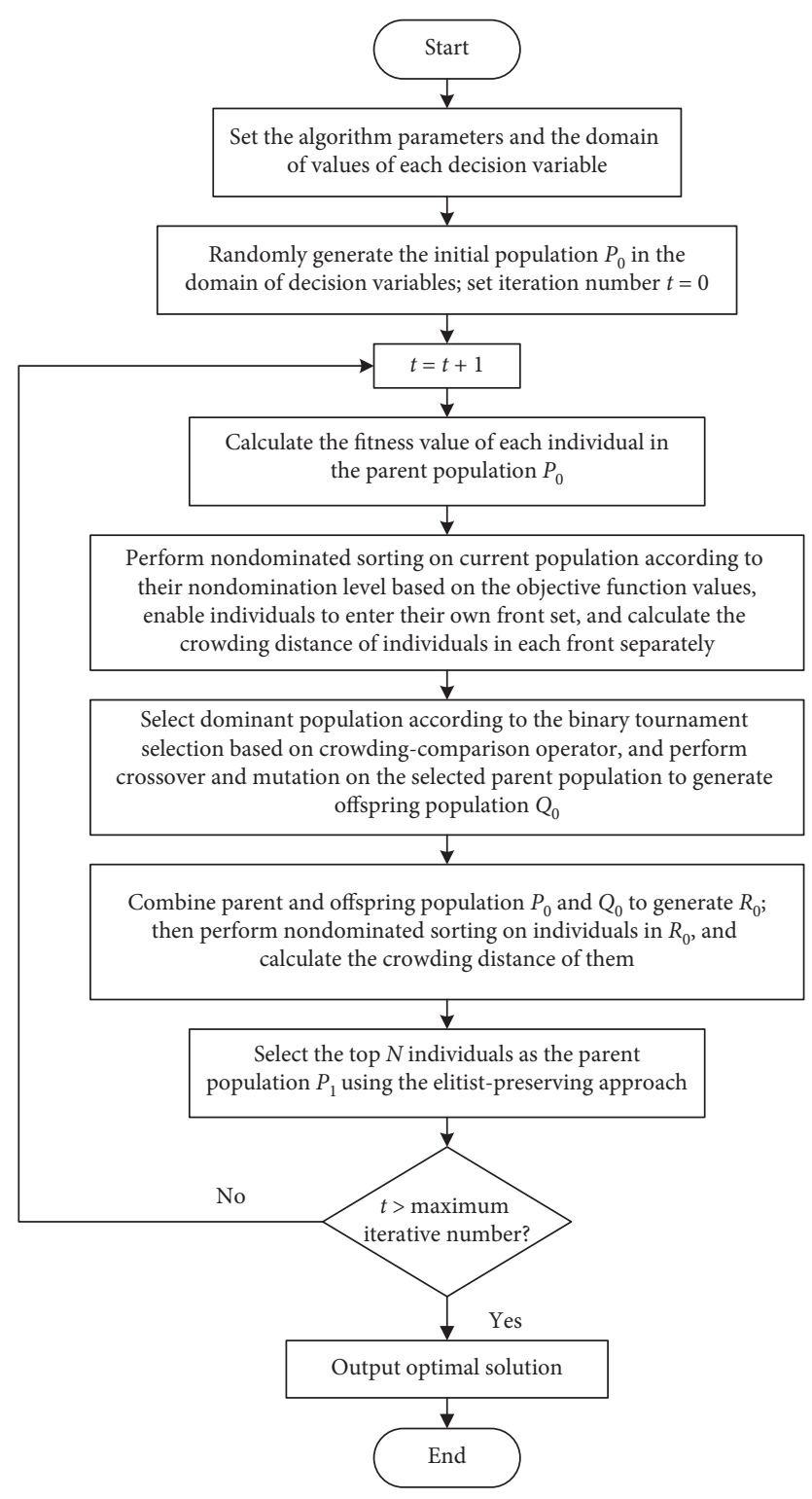

FIGURE 4: Flowchart of NSGA-II algorithm calculation.

Step 5. Select dominant population according to the binary tournament selection based on crowdingcomparison operator, and perform crossover and mutation on the selected parent population to generate offspring population $Q_{0}$.

Step 6. Combine parent and offspring populations $P_{0}$ and $Q_{0}$ to generate $R_{0}$; then perform nondominated sorting on individuals in $R_{0}$, and calculate the crowding distance of them.

Step 7. Select the top $N$ individuals as the parent population $P_{1}$ using the elitist-preserving approach.

Step 8. Determine whether the algorithm has reached the set maximum iteration number. If so, stop optimization and output the optimal solution. Otherwise, return to Step 3 and repeat the above operation until the set maximum number of iterations is reached.

\section{Empirical Analysis}

\subsection{Data Setting and Instructions}

4.1.1. Case Background. To verify the feasibility and effectiveness of the strategy proposed in this paper, the data of new energy electric vehicles used in summer in a municipality directly under the Central Government are taken as research objects. We selected six municipal districts in the city for research. For convenience, they are expressed by the letters A-E. The municipal district is a core component and regional development center of the city and is characterized by a concentrated population, close regional connections, and strong mobility. The characteristics of these municipal districts lay the foundations for carrying out the zonal and TOU pricing strategy for this paper.

After collecting the operational data from the charging stations and other relevant information, this paper analyzes the uncertain factors according to the power supply demand of each region and the actual operation of the charging stations; the aim is to improve the operating revenues of the charging station and to guide EV users to charge reasonably according to pricing strategy. Zonal pricing is to price the electricity selling price at charging stations in different regions. Using the data of the number of electric vehicles, charging stations, and the efficiency of charging stations in different regions, the optimal pricing strategies in different regions are analyzed. On this basis, TOU pricing is to price the electricity selling price of different regions in different time periods. According to the peak and valley situation of the traffic flow and the working efficiency of the charging station in different periods, and considering the objectives of user benefit, operator benefit, and grid fluctuation and multiple constraints, the optimal charging price of different regions in different time periods is determined by comprehensive analysis [50]. Thus, we can achieve differentiated pricing strategies in different regions for different time periods.

4.1.2. Data Setting. To facilitate the analysis, we set the following parameters. Due to the characteristic that EVs stay in residential or working areas for a long time, this paper assumes that EVs are charged at a constant power and slow speed. The sample number of EVs was 20000 with $70 \mathrm{kWh}$ battery capacity and $7.3 \mathrm{~kW}$ charging power. The minimum control period of charging power of EV charging station is 1 hour, the charging price before optimization is $1.5 \mathrm{yuan} /$ $\mathrm{kWh}$, and the maximum charging power transfer is $95 \%$. On this basis, the initial data of EV ownership and charging stations are shown in Figure 5.

Notes. Number of electric vehicles per charging=The number of electric vehicle/The number of charging stations.

From Figure 5, we can see that in the areas selected in this paper, regions $C$ and $D$ have a sufficient number of EVs, but a relatively inadequate supply of charging stations, while region $\mathrm{E}$, with a relatively small number of $\mathrm{EVs}$, has a 


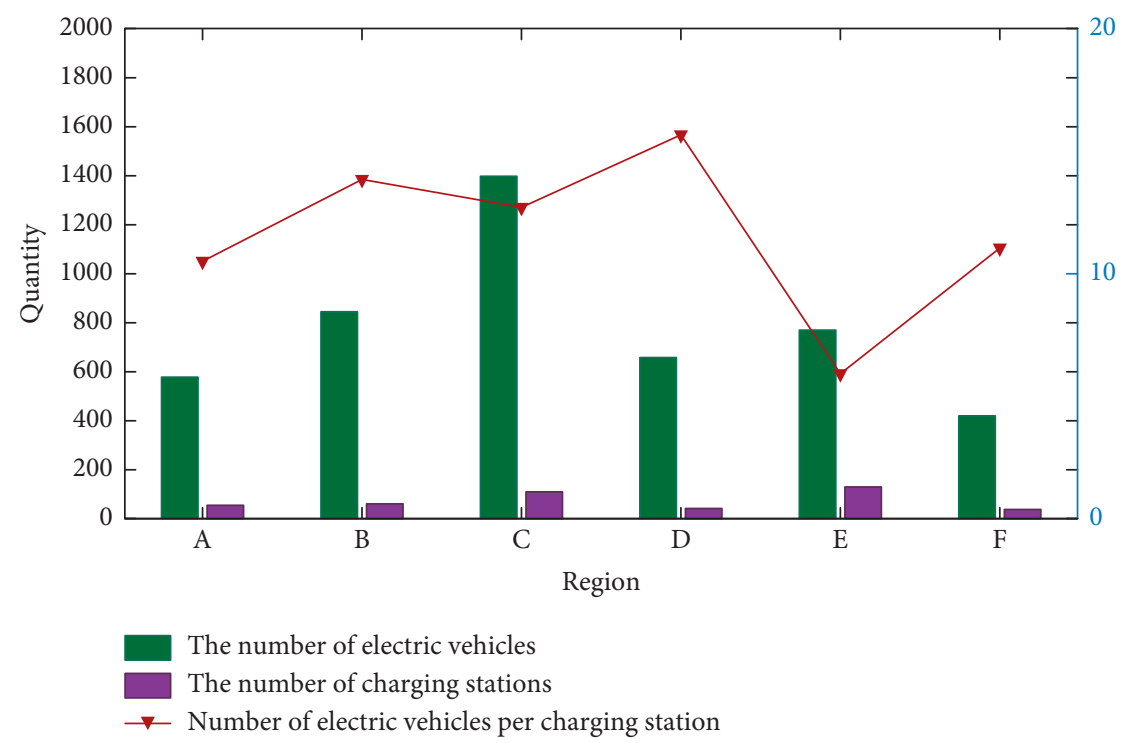

FIgURE 5: Contrast chart of electric vehicle ownership and charging station.

relatively large number and sufficient supply of charging stations. In the selected case, the demand for charging stations varies in different regions. For instance, in region $\mathrm{D}$, which has a higher number of EVs per charging station, the charging stations may be inadequate, with $\mathrm{EV}$ users needing to wait in line during the peak periods of charging, while in region $\mathrm{E}$, which has a lower number of EVs per charging station, the utilization rate is low owing to the desolation of some charging stations for weeks and months. Expanding charging stations in places where EVs are in great demand can solve this problem, but the execution is more difficult and will be restricted by technology, venue, and other aspects. The formulation of electricity pricing policies in different regions that guide users to decentralize charging (charging in adjacent areas with sufficient charging stations) can not only reduce the charging cost of users but also increase the utilization rate of charging stations and reduce the waiting time of charging queues, providing a basis for zonal pricing.

\subsubsection{Analysis of the Influence of Unguided EV Charging on} Power Grid. To analyze the influence of unguided charging behaviors of electric vehicles on the grid, we have drawn the daily demand data of charging vehicles and the original data of the conventional load of the power grid in the corresponding analysis period. Figure 6 shows the comparison of daily charging demand of EVs and daily load curves of the power grid on a given day.

As seen from Figure 6(a), the daily demand curve of EV charging is a normal distribution. The early peak period of charging commences from 8:00 am to 3:00 pm, and the peak of night charging starts from 18:00 to 20:00, which is consistent with people's life routine. Compared with the changes of daily load curve from Figure 6(b), it can be seen that the trend of charging peak is consistent with that of power consumption peak. That is, this unguided and spontaneous charging behavior increases the fluctuation on the grid. Charging in the peak period of electricity consumption will undoubtedly increase the load pressure on the grid and further widen the gap between the peak load (maximum load) and low load (minimum load). As we all know, electricity cannot be stored. Power generation, transmission, and use should be completed instantaneously, and the ideal load curve should be a horizontal straight line. In this event, the generator unit can operate stably for a long time with the lowest operation cost. However, there will be incapability to emerge frequent starts and stops of electric generating units and frequent dispatching of the power grid. The peak-valley difference refers to the difference between the maximum load and the minimum load in a certain period of time. An increase in the peak-valley difference means that we need to shut down more units in the low valley and start more units in the peak valley. However, frequent starts and stops of a unit will not only shorten its service life but also increase its use cost. Additionally, it will further increase the fluctuation of the power grid, bringing security risks to the power grid and increasing the difficulty of power grid dispatching. Charging during the peak period of the grid load will further increase the peak load and widen the peak-to-valley difference in the load, which will adversely affect the safety and economy of the grid. Under the circumstances, the formulation and implementation of TOU pricing can make users respond to the price and guide users to charge during the lowest periods of power consumption, thus achieving the win-win goals of reducing user charging costs, suppressing load fluctuation of the power grid, and ensuring the safety of the power grid operation.

4.2. Optimization Strategy for Zonal Pricing. According to formulae (1)-(3) and the principle of profit maximization, this paper optimizes the charging price of 6 regions in a city. Combined with the data of electric vehicle ownership and charging demand in different regions, we can get the optimal pricing results for each region, as shown in Table 1 and Figure 7. 


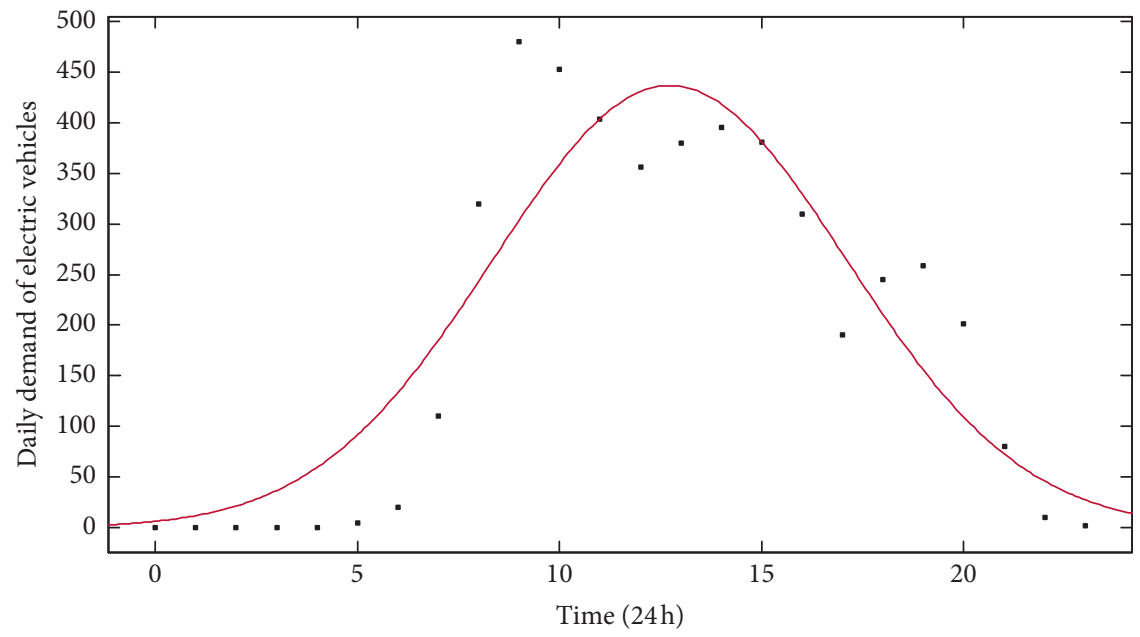

- Daily demand of electric vehicles

_ Fitting of normal distribution curve

(a)

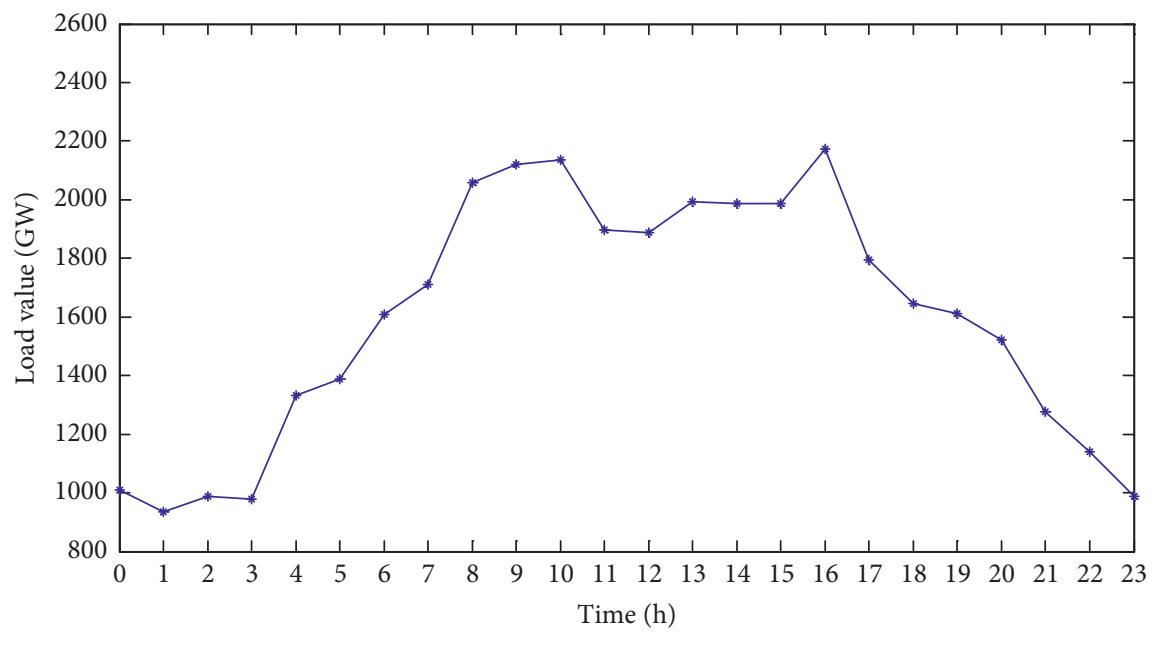

(b)

Figure 6: Comparison of daily charging demand of electric vehicles and daily load curves of power grid. (a) Daily demand curve of charged vehicles. (b) Graph of basic daily load curve of power grid.

TABLE 1: Optimal pricing of electric vehicle charging in various regions of a city.

\begin{tabular}{|c|c|c|c|c|c|}
\hline \multirow{2}{*}{$\begin{array}{l}\text { Regions } \\
\text { A }\end{array}$} & \multirow{2}{*}{$\begin{array}{c}\text { Number of EVs } \\
578\end{array}$} & \multirow{2}{*}{$\begin{array}{c}\text { Supply-demand ratio } \\
\text { for charging station }\end{array}$} & \multicolumn{2}{|c|}{$\begin{array}{c}\text { Daily demand (kW) } \\
\text { (before and after } \\
\text { optimization) }\end{array}$} & \multirow{2}{*}{$\begin{array}{c}\text { Optimal price } \\
\text { (yuan/kWh) } \\
1.77\end{array}$} \\
\hline & & & 245 & 282 & \\
\hline B & 845 & 13.85 & 478 & 351 & 1.90 \\
\hline C & 1398 & 15.67 & 835 & 768 & 1.87 \\
\hline D & 758 & 12.71 & 393 & 275 & 2.04 \\
\hline E & 670 & 5.92 & 269 & 343 & 1.25 \\
\hline $\mathrm{F}$ & 420 & 11.05 & 260 & 230 & 1.81 \\
\hline
\end{tabular}



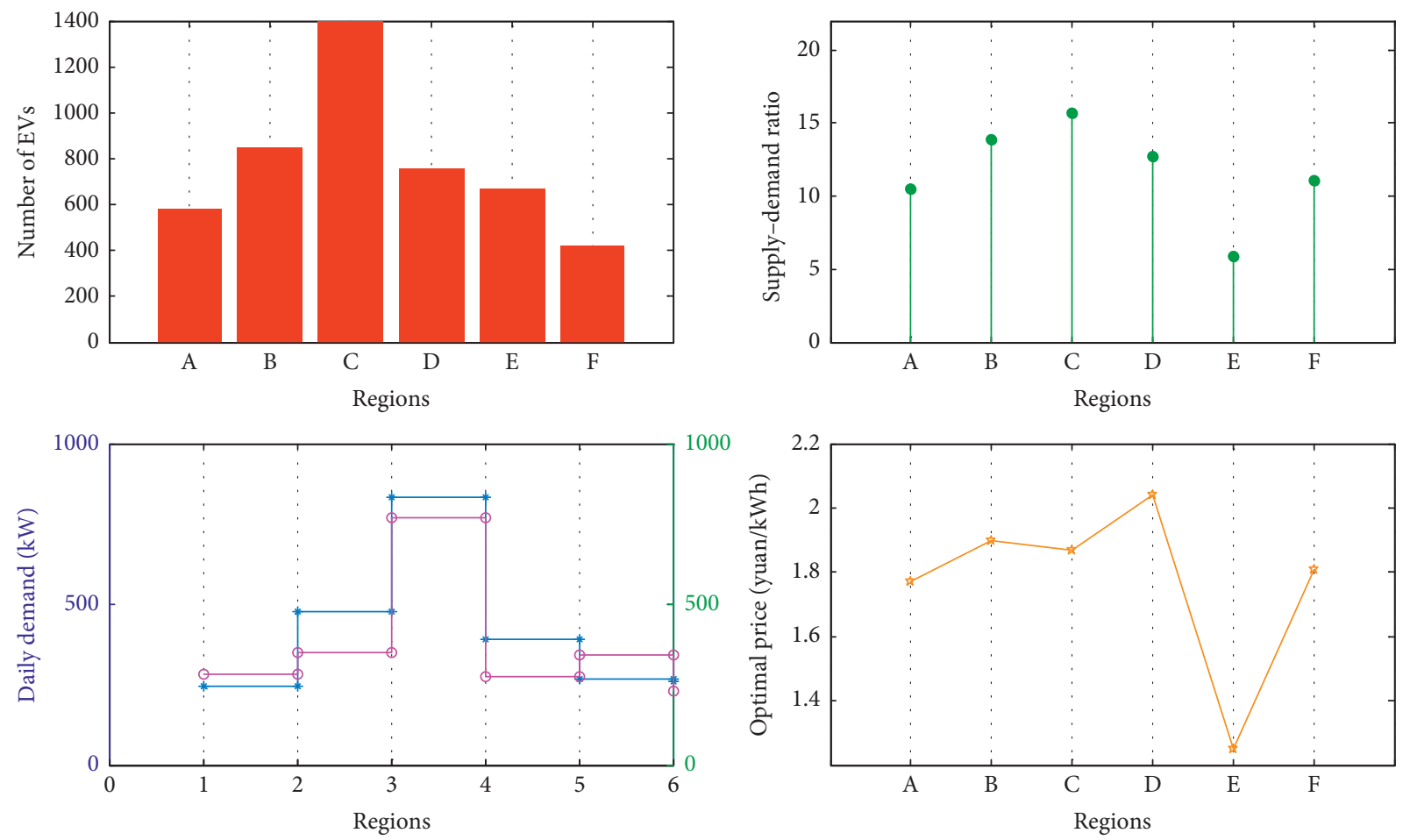

FiguRE 7: Variations before and after optimization in different regions.

Compared to the previous unified electricity price, different regions have different pricing after optimization. In Region $\mathrm{A}$, for example, the charging price before optimization is 1.5 yuan/kWh (including 0.8 yuan $/ \mathrm{kWh}$ for electricity price and 0.7 yuan/kWh for service fee), and the optimized charging price is 1.77 yuan/kWh, with an increase of $18 \%$. Compared with the supply-demand ratio for EV charging stations, there is a positive correlation between them. That is, the greater the ratio of supply-demand for $\mathrm{EV}$ charging stations is, the higher the charging price for the region is. When the ratio is large, there are more EVs and fewer charging stations in this region. At the same moment, it is likely that there are not enough charging stations and charging needs lead to queuing and other phenomena. According to the theory of supply and demand, when demand exceeds supply, the prices rise. Some users can be guided into changing their charging behavior and charging in adjacent regions with a lower charging price, which can reduce the charging pressure. After optimization, the daily demand for EV charging in each region has also shifted. In Region $\mathrm{E}$, which has a lower charging price, the daily demand has increased from $269 \mathrm{~kW}$ to $343 \mathrm{~kW}$, with a $27.5 \%$ rise, while in Region D, with the highest charging price, there is a downward trend in daily charging demand. That is, to a certain extent, the charging behavior is transferred from the high-price region to the low-price region. The zonal pricing strategy can effectively guide users to decentralized charging, improve the utilization efficiency of charging stations, and reduce queuing time due to charging congestion. However, relying solely on the zonal pricing strategy cannot solve the impact of large-scale electric vehicle charging load on grid security. Additionally, we believe further study into the guiding role of pricing strategies for users in different periods based on zonal pricing is required.

4.3. Optimization Strategy for TOU Pricing. According to the load change of 24 hours in a day shown in Figure 6, to reduce the peak-to-valley difference in the daily load curve and to make the charging load of electric vehicles reach the effect of peak-cutting and valley-filling, this paper first divides the time period into the peak, flat, and valley of the daily load, as shown in Table 2.

The TOU pricing strategy in this paper is analyzed on the foundation of this division. The optimization model is solved by programming with MATLAB. The parameters of NSGAII settings are as follows. The population number is 50 , the maximum number of iterations is 200 , the crossover rate is 0.8 , and the variation rate is 0.3 . The optimized time window for scrolling is 9 .

In this paper, the charging of electric vehicles is arranged in disorderly mode and orderly mode. Disorderly charging refers to the random charging behavior of electric vehicles without a guidance mechanism. Orderly charging refers to the arrangement of charging according to the optimal pricing strategy proposed by the charging station. Before optimization, the impact of disordered charging behavior on grid load is quantitatively analyzed, as shown in Figure 8. The black solid line represents the original load of the power grid, and the purple dotted line indicates the load condition after the superimposing of disordered charging for EVs. It can be seen clearly from the figure that the disordered charging behavior further 
TABle 2: Time division for TOU price.

\begin{tabular}{lc}
\hline Time period & Specific classification \\
\hline Peak & $8: 00-12: 00 ; 14: 00-16: 00 ; 18: 00-20: 00$ \\
Flat & $12: 00-14: 00 ; 16: 00-18: 00 ; 20: 00-24: 00$ \\
Valley & $0: 00-7: 00$ \\
\hline
\end{tabular}

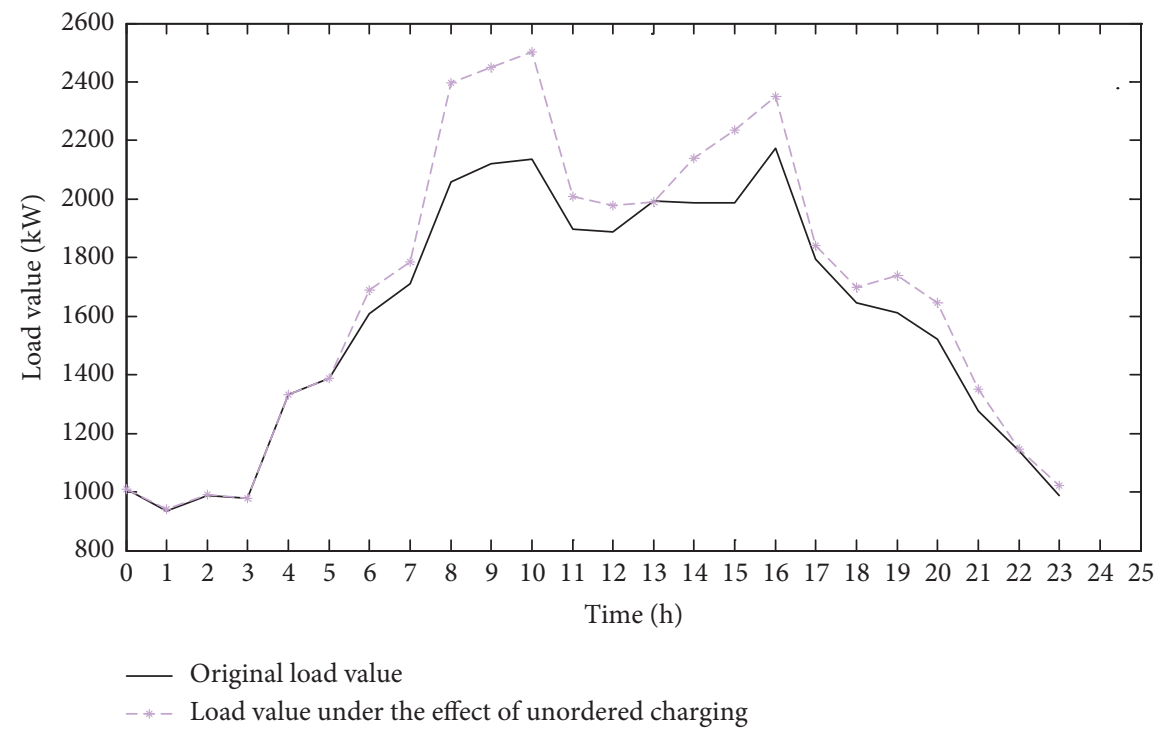

FIGURE 8: Influence of disordered charging behavior on grid load.

increases the load peak from the original $2173.5 \mathrm{GW}$ to $2503 \mathrm{GW}$, and the peak-to-valley difference ratio rises from $56.98 \%$ to $62.45 \%$, which enlarges the operating pressure on the grid. Thus, there is an urgent need to guide and control the charging behavior of EVs through a price mechanism.

Based on the zonal pricing, this paper studies the impact of TOU pricing in different regions on the charging behavior of EVs, mainly considering the peak, flat, and valley periods. The optimization results are shown in Table 3 by NSGA-II optimization. The corresponding user satisfaction and the grid load curve under the orderly charging are obtained as shown in Figures 9 and 10.

As seen from Figure 9, the user satisfaction with the optimized TOU price has significantly improved [51]. Among them, it mainly reflects in the satisfaction with the amount of electricity expenditure. Under the premise of guaranteeing the trip plan, the user's expenditure on the charging cost has been reduced, which will reach an overall optimal state. Figure 10 shows the guiding effect of optimized TOU price on electric vehicle users. The optimized grid load distribution is more uniform with a lower variance of the load. The load fluctuation is more gradual with a nearly $14 \%$ reduction in the peak-to-valley difference, which is conducive to the safety of the grid operation.
Moreover, the average rate of electricity transfer of EV users is $65 \%$. That is, comprehensive strategies of zonal pricing and TOU pricing can motivate users to change their original electricity usage habits and transfer the charging period from the peak load period to the low valley period of the grid and transfer the charging region from a dense area with fewer charging stations to areas with sufficient charging stations. This not only improves the utilization efficiency of charging stations in various regions but also plays a role in cutting peaks and filling valleys, which is conducive to the safer and more orderly operation of power grids and charging stations.

For a more intuitive understanding, the impact of the optimized pricing strategy on the charging power arrangement of EVs, this paper randomly selected $150 \mathrm{EVs}$ and plotted the charging power distribution, as shown in Figure 11 below.

By comparing the data of the above graphs, it can be seen that after adopting the optimized pricing strategy, the charging probability of EVs in peak period is significantly reduced, and the charging load time range of EVs is extended, which can distribute the charging load of EVs in a longer period. In this way, the fluctuation of load in the power grid can be smoothed more effectively, and the impact on the power grid can be reduced. 
TABLE 3: TOU tariffs of peak-flat-valley period in different regions.

\begin{tabular}{lcccc}
\hline Region & Peak period & Flat period & Valley period & Price before optimization \\
\hline A & 1.89 & 1.45 & 1.53 & 1.77 \\
B & 2.21 & 1.80 & 1.65 & 1.90 \\
C & 2.09 & 1.77 & 1.60 & 1.87 \\
D & 2.35 & 1.86 & 1.74 & 2.04 \\
E & 1.50 & 0.98 & 1.12 & 1.25 \\
F & 1.94 & 1.72 & 1.58 & 1.81 \\
\hline
\end{tabular}

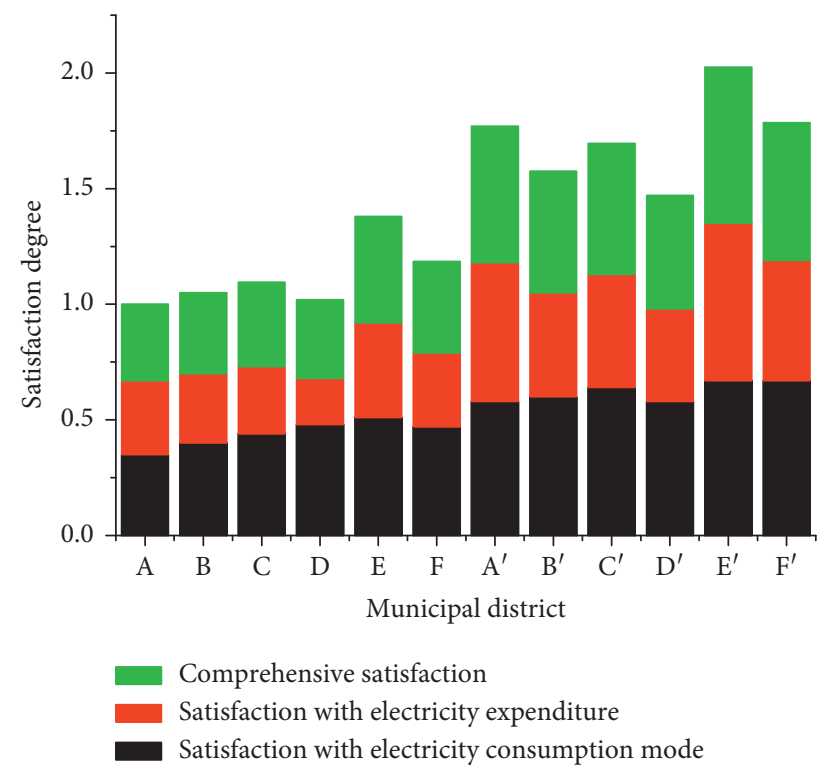

Figure 9: User satisfactions before and after optimization. A to E represent satisfaction before optimization and $A^{\prime}$ to $E^{\prime}$ represent satisfaction after optimization.

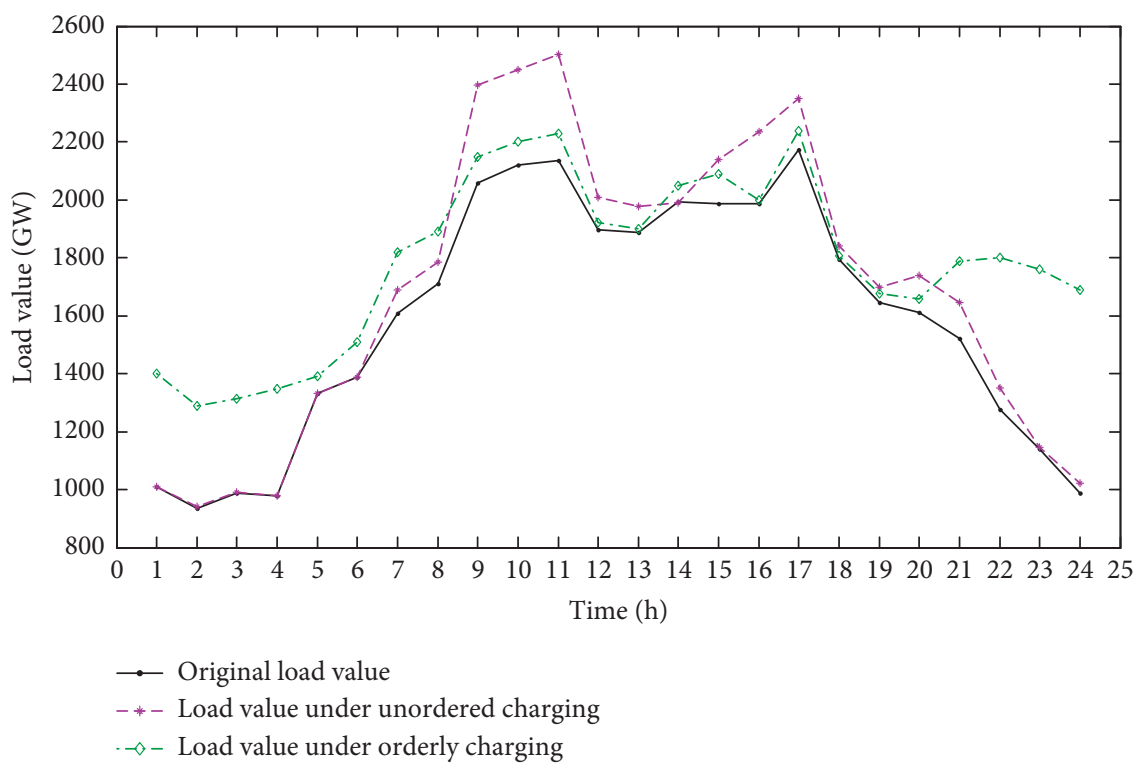

FIGURE 10: Load curve of power grid under ordered charging behavior. 


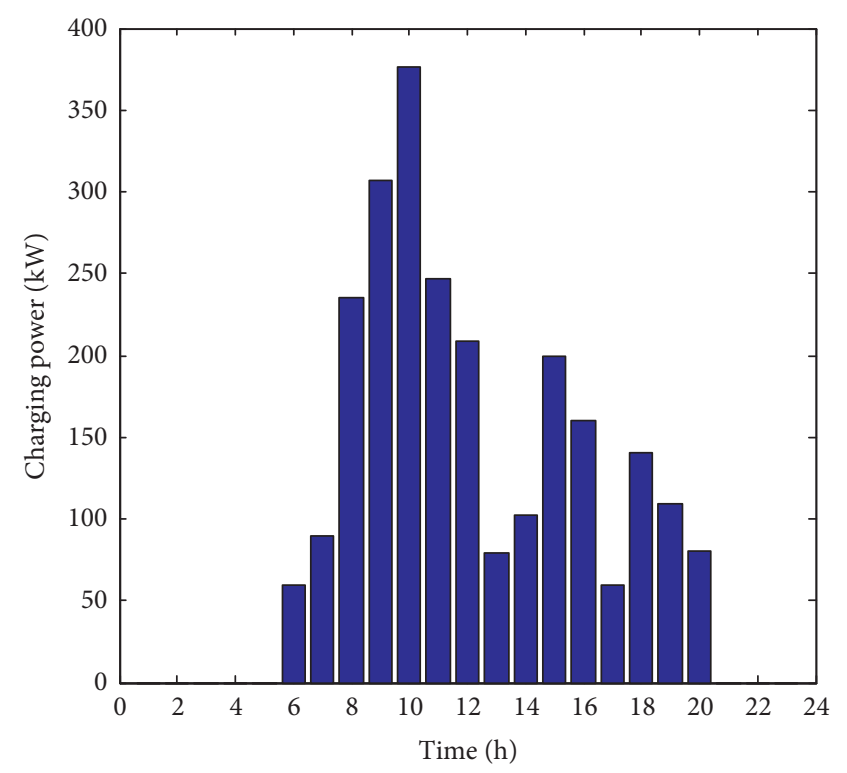

(a)

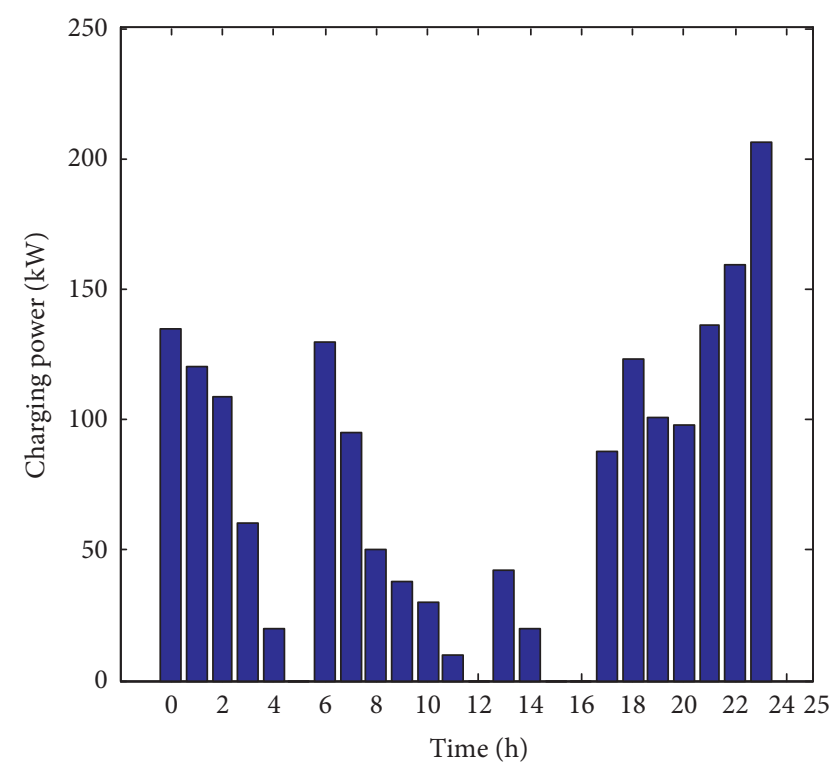

(b)

FIGURE 11: Charging power distribution before and after optimization of 150 EVs.

\section{Conclusion}

Electric vehicles, with clean electricity as fuel, can lessen dependency on fossil fuels and reduce greenhouse gas emissions. Promoting green and low-carbon behavior is vital. Based on the analysis of the charging characteristics of EVs, and considering the problems of large fluctuation on the grid and the imbalance in distribution and utilization of charging stations, a comprehensive optimization model based on zonal and TOU pricing for EVs is proposed in this paper. The empirical analysis is carried out with 6 municipal regions in a municipality directly under the Central Government as the research object. Compared with the disorderly charging behavior of EVs, the following conclusions are obtained:

(1) Formulating the charging price in different regions is beneficial to guide users to perform decentralized charging. The research shows that reasonable zonal pricing can effectively guide users to charge in adjacent areas and can effectively alleviate the charging pressure in crowded areas. The price signal is conducive in guiding the user to select a suitable charging station in advance, which can not only reduce the charging cost of the user but also improve the utilization efficiency of the charging station and increase the operating income of the power grid.

(2) Establishing a reasonable time-of-use price of peakvalley-flat is conducive to guiding users into choosing a reasonable charging time and optimizing the charging load of electric vehicles. The results show that, under the guidance of TOU pricing, the charging period of EVs is lengthened and the charging load is evenly distributed for a longer period. It can more effectively smooth the fluctuation of the grid load and alleviate the impact on the grid.
(3) Single zonal pricing strategy cannot optimize the daily load curve. Meanwhile, a single TOU pricing strategy cannot change the charging path of users and improve the utilization efficiency of charging stations. The rationality of zonal and TOU pricing strategy determines the user satisfaction, which in turn affects the user's electricity consumption behavior, finally achieving the effect of "shifting the peaks and filling the valley," calming the load fluctuation of the power grid to ensure a benefit for all parties and the safe operation of the power grid.

\section{Data Availability}

The data that support the findings of this study are available from the authors upon request.

\section{Conflicts of Interest}

The authors declare that there are no potential competing interests regarding the publication of this paper. All authors have seen the manuscript and approved to submit it.

\section{Authors' Contributions}

X. X. M., N. D. X., L. Y., and S. L. J. designed the experiments; N. D. X. provided guidance on manuscript preparation and supervised the whole work; X. X. M., L. Y., and S. L. J. conducted the experiments, analyzed the data, and wrote the manuscript.

\section{Acknowledgments}

The authors would like to acknowledge the financial support from the National Natural Science Foundation of China 
(Grant no.71804045) and the 2018 Key Projects of Philosophy and Social Sciences Research, Ministry of Education, China (Grant no. 18JZD032). This paper is also supported by the 111 Project (B18021) and the Fundamental Research Funds for the Central Universities (2018ZD14 and 2020MS045).

\section{References}

[1] J. Guo, X. Zhang, F. Gu, H. Zhang, and Y. Fan, "Does air pollution stimulate electric vehicle sales? Empirical evidence from twenty major cities in China," Journal of Cleaner Production, vol. 249, Article ID 119372, 2019.

[2] Z. Hu, K. Zhan, H. Zhang, and Y. Song, "Pricing mechanisms design for guiding electric vehicle charging to fill load valley," Applied Energy, vol. 178, pp. 155-163, 2016.

[3] Y. Ma, T. Shi, W. Zhang, Y. Hao, J. Huang, and Y. Lin, "Comprehensive policy evaluation of NEV development in China, Japan, the United States, and Germany based on the AHP-EW model," Journal of Cleaner Production, vol. 214, pp. 389-402, 2019.

[4] Y. Li, P. Zhang, and Y. Wu, "Public recharging infrastructure location strategy for promoting electric vehicles: a bi-level programming approach," Journal of Cleaner Production, vol. 172, pp. 2720-2734, 2018.

[5] B. Hu, Y. Feng, J. Sun, Y. Gao, and J. Tan, "Driving preference analysis and electricity pricing strategy comparison for electric vehicles in smart city," Information Sciences, vol. 504, pp. 202-220, 2019.

[6] A. F. Roberto, "A more realistic approach to electric vehicle contribution to greenhouse gas emissions in the city," Journal of Cleaner Production, vol. 172, pp. 949-959, 2018.

[7] R. Ju, "Electric vehicle charging station constraint conditions and comprehensive benefit analysis," East China Electric Power, vol. 39, pp. 547-550, 2011, in Chinese.

[8] C. C. Lluc, M. L. Egoitz, A. G. Beatriz, and N. Nerea, "Sustainability analysis of the electric vehicle use in Europe for $\mathrm{CO}_{2}$ emissions reduction," Journal of Cleaner Production, vol. 127, pp. 425-437, 2016.

[9] R. Marco, H. Allan, and M. Denise, "Can electric vehicles significantly reduce our dependence on non-renewable energy? Scenarios of compact vehicles in the UK as a case in point," Journal of Cleaner Production, vol. 201, pp. 1043-1051, 2018.

[10] S.-B. Tsai, Y. Xue, J. Zhang et al., "Models for forecasting growth trends in renewable energy," Renewable and Sustainable Energy Reviews, vol. 77, pp. 1169-1178, 2017.

[11] X. Zhao, Q. Yu, J. Ma, Y. Wu, M. Yu, and Y. Ye, “Development of a representative EV urban driving cycle based on a k-means and SVM hybrid clustering algorithm," Journal of Advanced Transportation, vol. 2018, Article ID 1890753, 18 pages, 2018.

[12] Z. Lv, B. Hu, and H. Lv, "Infrastructure monitoring and operation for smart cities based on IoT system," IEEE Transactions on Industrial Informatics, vol. 16, no. 3, pp. 1957-1962, 2020.

[13] T. Yi, C. Zhang, T. Lin, and J. Liu, "Research on the spatialtemporal distribution of electric vehicle charging load demand: a case study in China," Journal of Cleaner Production, vol. 242, Article ID 118457, 2020.

[14] P. Hu, Z. Tan, G. Qiu et al., "Overview of the development of electric vehicles," Electrotechnical Application, vol. 37, pp. 79-85, 2018, in Chinese.

[15] J. Ma, X. Liu, Y. Chen et al., "Current status and countermeasures for China's new energy automobile industry and technology development," China Journal of Highway and Transport, vol. 31, pp. 1-19, 2018, in Chinese.

[16] F. Gu, J. Guo, X. Yao, P. A. Summers, S. D. Widijatmoko, and P. Hall, "investigation of the current status of recycling spent lithium-ion batteries from consumer electronics in China," Journal of Cleaner Production, vol. 161, pp. 765-780, 2017.

[17] L. Widijatmoko and Z. Hanwen, "An ontology constructing technology oriented on massive social security policy documents," Cognitive Systems Research, vol. 60, pp. 97-105, 2020.

[18] K. M. Tan, V. K. Ramachandaramurthy, and J. Y. Yong, "Integration of electric vehicles in smart grid: A review on vehicle to grid technologies and optimization techniques," Renewable and Sustainable Energy Reviews, vol. 53, pp. 720732, 2016.

[19] K. Guo, "Research on location selection model of distribution network with constrained line constraints based on genetic algorithm," Neural Computing and Applications, vol. 32, no. 6, pp. 1679-1689, 2019.

[20] D. Yu, H. Zhu, W. Han, and D. Holburn, "Dynamic multi agent-based management and load frequency control of PV/ Fuel cell/ wind turbine/ CHP in autonomous microgrid system," Energy, vol. 173, no. 15, pp. 554-568, 2019.

[21] C. A. Klöckner, A. Nayum, and M. Mehmetoglu, "Positive and negative spillover effects from electric car purchase to car use," Transportation Research Part D: Transport and Environment, vol. 21, pp. 32-38, 2013.

[22] B. Zhou, F. Yao, T. Littler, and H. Zhang, "An electric vehicle dispatch module for demand-side energy participation," Applied Energy, vol. 177, pp. 464-474, 2016.

[23] P. Finn, C. Fitzpatrick, and D. Connolly, "Demand side management of electric car charging: benefits for consumer and grid," Energy, vol. 42, no. 1, pp. 358-363, 2012.

[24] W. Kempton and T. Kubo, "Electric-drive vehicles for peak power in Japan," Energy Policy, vol. 28, no. 1, pp. 9-18, 2000.

[25] C. D. White and K. M. Zhang, "Using vehicle-to-grid technology for frequency regulation and peak-load reduction," Journal of Power Sources, vol. 196, no. 8, pp. 3972-3980, 2011.

[26] C.-H. Chen, "An arrival time prediction method for bus system," IEEE Internet of Things Journal, vol. 5, no. 5, pp. 4231-4232, 2018.

[27] Y. Zhang, Q. He, Y. Xiang et al., "Low-cost and confidentiality-preserving data acquisition for internet of multimedia things," IEEE Internet of Things Journal, vol. 5, no. 5, pp. 3442-3451, 2017.

[28] V. K. Senthil Ragavan, M. Elhoseny, and K. Shankar, "An enhanced whale optimization algorithm for vehicular communication networks," International Journal of Communication Systems, 2019, In press.

[29] X. J. Qi, D. W. Li, and S. Y. Ji, "Orderly charging strategy of electric vehicles in residential areas with power limitation," Power Grid Technology, vol. 40, no. 12, pp. 3715-3721, 2016, in Chinese.

[30] F. Salah and C. M. Flath, "Deadline differentiated pricing in practice: marketing EV charging in car parks," Computer Science-Research and Development, vol. 31, no. 1-2, pp. 3340, 2014.

[31] F. He, Y. Yin, J. Wang, and Y. Yang, "Sustainability SI: optimal prices of electricity at public charging stations for plug-in electric vehicles," Networks and Spatial Economics, vol. 16, no. 1, pp. 131-154, 2013.

[32] T. Ikegami, H. Yano, K. Kudo, and K. Ogimoto, "Effects of smart charging of multiple electric vehicles in reducing power generation fuel cost," Electrical Engineering in Japan, vol. 193, no. 2, pp. 42-57, 2015. 
[33] Y. Cao, S. Tang, C. Li et al., "An optimized EV charging model considering TOU price and SOC curve," IEEE Transactions on Smart Grid, vol. 3, no. 1, pp. 388-393, 2012.

[34] K. Lu, S. Liu, X. Niu, W. Xue, Y. zhu, and Z. Zhu, "Pricing method of electric vehicle charging by using cost-benefit analysis," Proceedings of the CSU-EPSA, vol. 26, pp. 76-80, 2014, in Chinese.

[35] N. O'Connell, Q. Wu, J. Ostergaard, A. H. Nielsen, S. T. Cha, and Y. Ding, "Electric vehicle (ev) charging management with dynamic distribution system tariff," in Proceedings of the 2nd IEEE PES International Conference and Exhibition on Innovative Smart Grid Technologies University Manchester, Manchester, UK, 2011.

[36] A. Ghosh and V. Aggarwal, "Control of charging of electric vehicles through menu-based pricing," IEEE Transactions on Smart Grid, vol. 9, no. 6, pp. 5918-5929, 2018.

[37] S. Martinenas, A. B. Pedersen, M. Marinelli, and P. B. Andersen, "Electric vehicle smart charging using dynamic price signal," in 2014 IEEE International Electric Vehicle Conference (IEVC), December 2014.

[38] X. Dong, Y. Mu, X. Xu et al., "A charging pricing strategy of electric vehicle fast charging stations for the voltage control of electricity distribution networks," Applied Energy, vol. 225, pp. 857-868, 2018.

[39] Y. Cao, Q. Wang, W. Cheng, S. Nojavan, and K. Jermsittiparsert, "Risk-constrained optimal operation of fuel cell/photovoltaic/battery/grid hybrid energy system using downside risk constraints method," International Journal of Hydrogen Energy, vol. 45, no. 27, pp. 14108-14118, 2020.

[40] X. Li, H. Li, J. Zhang, Y. Liu, Y. Niu, and N. Song, "Dynamic breakeven analysis on the charging price of electric vehicle charging station," in 2012 China International Conference on Electricity Distribution (CICED), Shanghai, China, September 2012.

[41] L. Pu, Q. Ai, W. Yu, and J. Chen, "Multi-agent elecetronic pricing strategy for electric vehicle charging cosidering customer satisfaction degree," Automation of Electric Power Systems, vol. 22, pp. 69-75, 2015, in Chinese.

[42] J. Cui, W. Luo, and N. Zhou, "Research on pricing model and strategy of electric vehicle charging and discharging based on multi view," Proceedings of the CSEE, vol. 15, 2018 in Chinese.

[43] B. Zhu, M. Zhang, L. Huang, P. Wang, B. Su, and Y. Wei, "Exploring the effect of carbon trading mechanism on China's green development efficiency: a novel integrated approach," Energy Economics, vol. 85, p. 104601, 2020.

[44] M. Elhoseny, X. Yuan, H. K. El-Minir, and A. M. Riad, "Extending self-organizing network availability using genetic algorithm," in Proceedings of the 5th International Conference on Computing Communication and Networking Technologies, ICCCNT, Hefei, China, July 2014.

[45] Y. Cao, Y. Li, G. Zhang, K. Jermsittiparsert, and M. Nasseric, "An efficient terminal voltage control for pemfc based on an improved version of whale optimization algorithm," Energy Reports, vol. 6, pp. 530-542, 2020.

[46] K. Deb, A. Pratap, S. Agarwal, and T. Meyarivan, "A fast and elitist multi-objective genetic algorithm: NSGA-II," IEEE Transactions on Evolutionary Computation, vol. 6, pp. 182197, 2002.

[47] G. B. Elias and W. N. John, "Multi-objective automatic calibration of SWAT using NSGA-II," Journal of Hydrology, vol. 341, no. 3-4, pp. 165-176, 2007.

[48] S. Debasis and M. M. Jayant, "Pareto-optimal solutions for multi-objective optimization of fed-batch bioreactors using nondominated sorting genetic algorithm," Chemical Engineering Science, vol. 60, no. 2, pp. 481-492, 2005.

[49] P. Murugan, S. Kannan, and S. Baskar, "NSGA-II algorithm for multi-objective generation expansion planning problem," Electric Power Systems Research, vol. 79, no. 4, pp. 622-628, 2009.

[50] T. Gaber, S. Abdelwahab, M. Elhoseny, and A. E. Hassanien, "Trust-based secure clustering in WSN-based intelligent transportation systems," Computer Networks, vol. 146, pp. 151-158, 2018.

[51] S.-B. Tsai, C.-Y. Huang, C. Yu, Q. Chen et al., "Using a mixed model to evaluate job satisfaction in high-tech industries," PLoS One, vol. 11, no. 5, Article ID e0154071, 2016. 